

\section{Automated Detormination of Irradiated Fuel Pin Centerlines for Gamma Scanning}

B. K. Barnes

J. N. Quintana

A. S. Murray
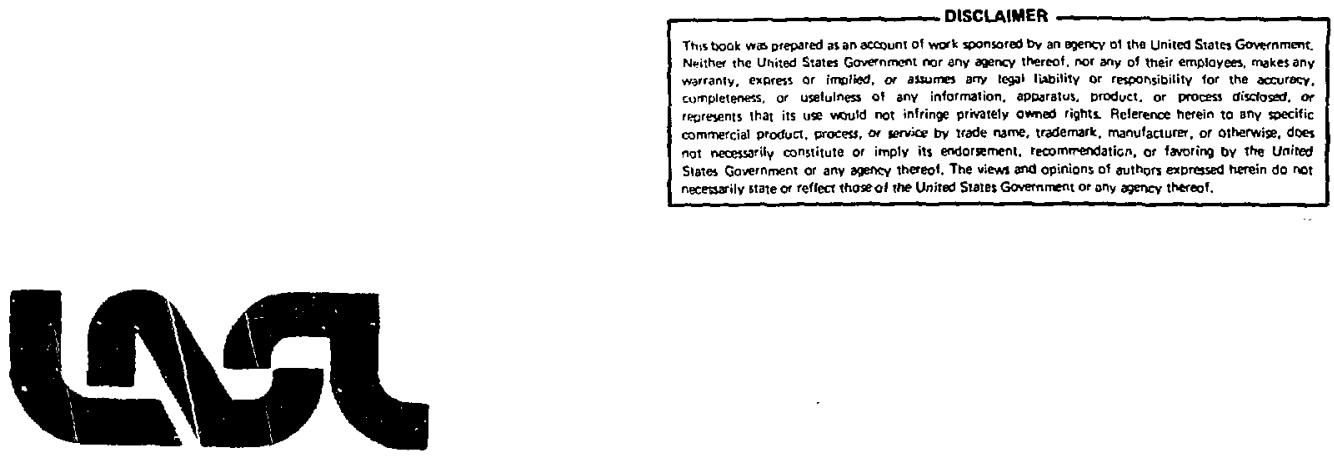


\title{
AUTOMATED DETERMINATION OF IRRADIATED FUEL PIN CENTERLINES FOR GAMMA SCANNING
}

\author{
B. K. Barnes, J. N. Quintsna, and A. S. Murray
}

\begin{abstract}
We describe a method for calculating the centerlines of irraciated fuel pins to be analyzed by gamma scanning. Fuel pin centering has been automated by computer control through a CAMAC link to the scanning mechanism. Rapidity and accuracy of the gamisa scanning process have been improved by replacing the former trial and error method with this automated technique.
\end{abstract}

\section{INTRODUCTION}

Gamma scanning is an important nondestructive technique for analysis of fuel pins. It can be applied to research and development in fuel pin technolcgy and to materials control by manufacturers of commercial fuel pins. A destructive examination, which can determine more accurataly the amounts of fission products and fissionable materials in an irradiated fuel pin, is extremely expensive and, in many cases, not feasible. Thus the highest possible degree of accuracy is demanded of a nondestructive analysis technique. The possible advent of commercial fast breeder reactors will increase the importance of high accuracy techniques because large amounts of tissionable materials and much reprocessing are associated with such reactors.

\section{THE PROBLEM}

Axial gamma scanning of an irradiated fuel pin requires an accurate determination of the fuel pin centerline. To avoid variation of the gamma-ray intersity with axial position, the fuel pin must remain centered in the volume-defining collimators as it is moved past them. Any significant deviation of the fuel pin centerline from the centerline of the collimators produces a decrease in the measured gamma-ray intensity because of the collimator geometry and the nonuniform response of the detector across its face.

Most irradiated fuel pins exhibit a degree of mechanical bowing greater than the amount (approximately $1 \mathrm{~mm}$ from end to end) that does not af fect significantly the gamma-ray intensity. ${ }^{1}$ A mechanical device has been used to hold the fuel pin centered in the collimators. Use of such a device, however, requires that the fuel pin be handled bare-a situation that, in the event of fission product leakage from the fuel pin, could lead to contamination of the scanning mechanism and the hot cell. Also, malfunction of the centering mechanism could cause damage to the fuel pin. To avoid the possibility of contamination or damage, fuel pins are scanned inside an alpha-particle containment canister, a thin-walled stainless steel tube sealed at both ends. A canister small enough to hold the fuel pin straight could be used, but loading a bowed fuel pin into such a tight container by manipulators inside a hot cell would be difficult and timeconsuming. Therefore, we use a more loosely fitting canister and the bow remains. The customary procedure for eliminating the effects of the bow has been to locate by trial and error a rotation and tilt of the canister such that the fuel pin remains on the centerline of the collimators as it is being axially scanned. 


\section{THE SOLUTION}

ln most cases, it is possible to determine a single rotation and tilt such that, for all axial positions, the fuel pin is centered in the collimators. Most fuel pins must therefore have a simple plane bow, as opposed to a spiral bow. For a simple plane bow, the required rotation and tilt can be calcliated from a set of initial measurements in the following manner.

Six diametral scans are made across the fuel pin, two at each of three axial positions corresponding to the approximate beginning, middle, and end of that portion of the fuel pin containing the enriched fuel. The fuel pin is rotated $90^{\circ}$ between the two scans at each axial position. From analysis of these six diametral scans, we can determine the threedimensional coordinates of the fuel pin centerline at three points $\left(x_{1}, y_{1}, z_{1}\right),\left(x_{2}, y_{2}, z_{2}\right)$, and $\left(x_{3}, y_{8}, z_{3}\right)$ where $z$ denotes the axial position of the centerline and $x$ and $y$ denote the diametral positions of the centerline for the two rotations $\left(90^{\circ}\right.$ relative to each other).

Assuming a simple plane bow of the fuel pin, these three points determine a plane, namely the plane of the fuel pin bow. If the equation of this plane is given by

$x+b y+c z+d=0$,

where $b, c$, and $d$ are constants determined from the coordinates of the three points, then the direction angles $\alpha, \beta$, and $\gamma$ of the line $\mathrm{P}$ normal to the bow plane are given ${ }^{2}$ by

$\cos \alpha=1 /\left(1+b^{2}+c^{2}\right)^{\frac{1}{2}}$. $\cos B=b /\left(1+b^{2}+c^{2}\right)^{\frac{1}{2}}$,

and

$\cos Y=c /\left(1+b^{2}+c^{2}\right)^{\frac{1}{2}}$.

The direction angles $\alpha_{z}, \beta_{2}$, and $\gamma_{2}$ of the directed line segment $+Z$ (the axis of rotation of the fuel pin) are given by

$\cos \alpha_{z}=\cos \pi / 2=0$,

$\cos B_{Z}=\cos \pi / 2=0$,

and

$\cos \gamma_{\mathrm{Z}}=\cos 0=1$.

The cosine of the angle $\phi$ between $P$ and $+Z$ is given by the sum of the products of the respective direction cosines."

$\cos \phi=\cos \alpha \cos \alpha_{Z}+\cos \beta \cos \beta_{Z}+\cos \gamma \cos \gamma_{Z}$

$=\cos \gamma$

By tilting the how plane an amount such that $\mathrm{P}$ and $+Z$ are perpendicular, the bow plane becomes parallel to the $\mathrm{X}$ axis. So, first we tilt the fuel pin by an angle of $90^{\circ}-\gamma$.

Next, we rotate $P$ so that it is parallel to the axis of the diametral scans (in our case, the $\mathrm{X}$ axis). From Fig. 1, we see that the angle $\delta$ between the $Y$ axis and the projection of $\mathrm{P}$ on the $\mathrm{X}-\mathrm{Y}$ plane is given by

$\cos \delta=\cos \beta / \sin Y$.

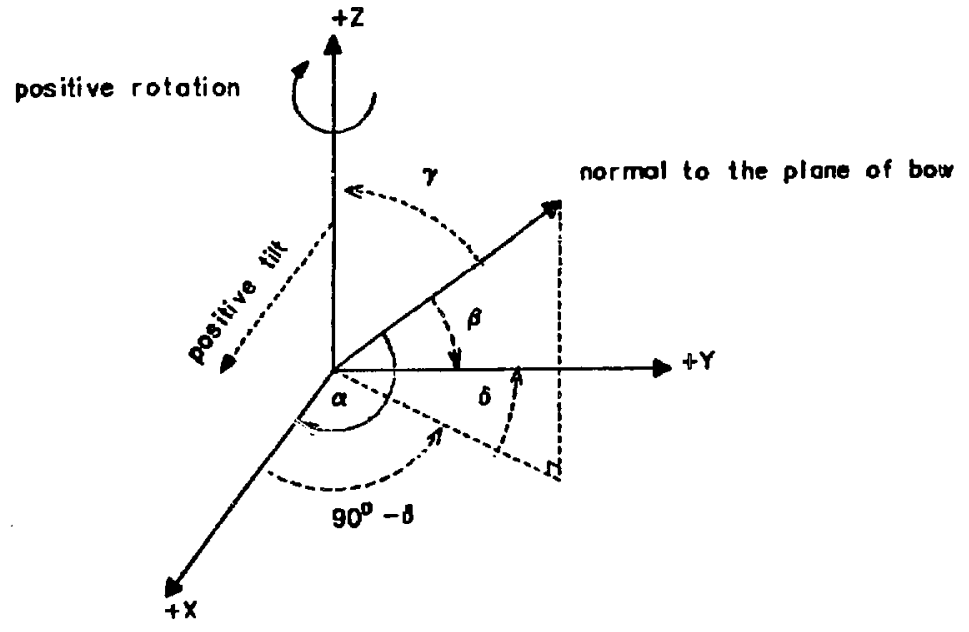

Fig. 1.

Geometry of the scanning mechanism. 
Therefore by rotating the bow plane by an angle of $90^{\circ}-\delta$ (where $\delta=\cos ^{-1}[(\cos \beta) /(\sin \gamma)]$, the bow plane becomes perpendicular to the $X$ axis.

\section{CONCLUSIONS}

In summary, having determined the direction angles of the normal to the fuel pin bow plane to be $\alpha, \beta$, and $\gamma$, we can make the bow plane perpendicular to the diametral scan direction by (a) tilting the fuel pin by $90^{\circ}-\gamma$ and (b) rotating the fuel pin by $90^{\circ}-\cos ^{-1}|(\cos \beta) /(\sin \gamma)|$. With this tilt and rotation, the fuel pin remains centered in the collimators during an axial scan. A computer program for the necessary calculations has been written and used on an HP-9820 calculator (Hewlett-Packard Co.), a P!P-8 computer (Digital Equipment Corp.), a CDC-7600 computer (Control Data Corp.) and an NI)6620 multichannel analyzer (Nuclear Data, Inc.). A FORTRAN version of this program is given in the Appendix.

A program to automate centering of the fuel pins has been written for the ND6620 multichannel analyzer. Computer control of the five degrees of freedom of the scanning mechanism (rotation, tilt, and motion along the $\mathrm{X}, \mathrm{Y}$, and $\mathrm{Z}$ axes) is achieved by a CAMAC link to the scanning mechanism. The program takes the required diametral scans, calculates the centerline coordinates and the required rotation and tilt, mies th: fuel pin, and checks the centerline. If necessary, the process is repeated until a satisfactory centerlico is located.

Automation of fuel pin centering reduces the time required for gamma scanning by typically one to two hours per fuel pin. Accuracy of the centerline so determined is greater; therefore, error in the data is reduced.

\section{REFERENCES}

1. J. R. Phillips, "New Techniques in Precision (iamma Scanning: Applications to Fast-Breeder Reactor Fuel Pins," Los Alamos Scientific Laboratory report LA-5260-T (July 1973).

2. I. M. H. Olmsted, Solid Analytic Geometry (Appleton-Century Crofts, New York, 1947), p. 15.

3. J. H. Kindle, Analytic Geometry (McGraw-Hill Book Co., New York, 1950), p. 105. 


\section{APPENDIX \\ FORTRAN VERSION OF THE PROGRAM ACl.}

LASL Identification No. LP-2024

C GOURCE. ACL (AUTONATIC CHNYRA LING)

ITTEGER DKS, GVAR, TITLE, AX, PIBST, TAPE, T, CURR, BLAN,, RYA,

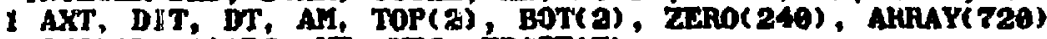

LOG ICAL * 1AADC, Yh, YTB, BRASE(T)

DIMENSION TITLE( 125, AADC(26), TAPE(5), TH(2), AR(360), JTITLE( 12)

$1, I T N(2), \operatorname{ROT}(6), \operatorname{ZPOS}(6), \mathrm{IABCTX}(32), \mathrm{X}(6), \operatorname{DATA}(240)$, START(6), $2 \operatorname{STOP}(6)$

BQU I VALEIYCE (TAPE( 4), TT), (IADCTX(29), BLOPE), (IADCTK( 31), OFFSET),

1 ( AR, ARRAY)

DATA AADC /1H: , IHA, 1HA, IBD, 1HC, 1H, 1H1, IB, 1H1, 1H, 1B4, 1HO, 1H9, 1H6

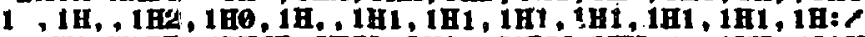

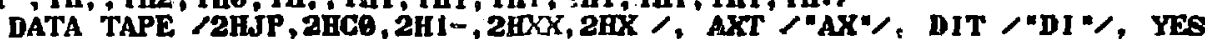

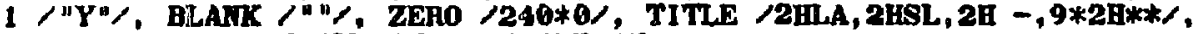

2 EAASE, $1 \mathrm{~L}, 1 \mathrm{HE}, 1 \mathrm{HA}, 1 \mathrm{HA}, 1 \mathrm{HS}, 1 \mathrm{HE}, 1 \mathrm{H}$

DIFHIN $=1000000$.

TUL $=7.120$

C TUL=TILT UPPER LIMIT > TLL=TILT LOWER LIMIT

WAITE $(7,500)$

WRITE $(7,490)$

WRITE $(7,600)$

WRITE $(7,230)$

WRITE $(7,490)$

WRITE (7, 509)

10 WRITE $(7,240)$

WAITE $(7.290) 2 \mathrm{~L}$

WRITE $(7,270)$

READ $(5,250)$ ARL

IF ( AZL. NE. O.) ZLEARL

$P P=(60,-Z L)+0.3$

c PP IS POSITIOH OF PIVOT POINT, USED TO CALCULATE

C NEW START AND ETOP POSITIONS AFTER TILTINC.

20 WRITE $(7,260)$

WHITE $(7,290)$ TOPF

WITE $(7,270)$

READ $(5,280)$ ATOPF

IF (ATOPF. NE. O) TOPF = ATOPF

WAITE $(7,300)$

WRITE $(7,290)$ BOTF

WRITE $(7,270)$

READ (5,2B6) ABOTF

IF ( ABOTF.NE.6.) BOTY ABOTE

STEP $=.026$

TIME $=.2$

NDIA $=6$

$\mathrm{ZPOS}(1)=\mathrm{TOPF}$

$\operatorname{ZPOS}(2)=(\mathrm{TOPF}+\mathrm{BOTF}) \mu$.

$\mathrm{ZPOS}(3)=\mathrm{BOTF}$

ZPOS $(4)=$ BOTT

$\operatorname{ZPOS}(5)=\operatorname{ZPOS}(2)$

$\operatorname{ZPOS}(6)=$ TOPF

CALL RUPOG (4, RO)

CALl ROPOS (5,TO) 
$\operatorname{ROT}(1)=\operatorname{AOT}(3)$

$\operatorname{ROT}(2)=\operatorname{AOT}(3)$

$\operatorname{ROT}(6)=10-.050$

ROT (5) $=\operatorname{ROT}(6)$

$\operatorname{ROT}(4)=\operatorname{FOT}(6)$

WAITE $(7,310)$

WRITE $(7,270)$

READ ( 5,360) IT

IF ( YN. NE. YES) GO TO 30

WATE $(7,320)$

gO TO 10

30 CALL SETPOS (2,32.4)

IF (TO.EQ.8.08) GO TO 40

WRITE $(7,300)$ TO

REAI $(5,360)$ Yi

IF ( YN. NE. YNS) GO TO 40

CALL SETPOS $(5.6 .080)$

$\mathrm{TO}=5.080$

$\mathbf{c}$

40 ConT inue

CALCULATE TAN OF ANGLE OF TILT FROH VERTICAL

USE TO CORRECT START AND GTOP POSITIONS

$T A=((T \theta-5.080) / 2) * 1.25 /$.24 .

DO 50 $\mathrm{L}=1$, $\mathrm{ND} \perp \mathrm{A}$

START $(L)=1.80+(\operatorname{ZPOS}(L)-P P) * T A$

$\operatorname{STOP}(L)=\operatorname{START}(L)+1.4$

50 CONT I NUE

C

CHAHGE ENERGY CAL , TO READ MARKGR IN IRChES.

CALL DECP ( 1, STEP. START 1$)$, IEAR

NPTS = NDIA* ( (STOP $(1)-$ START $(i)) /$ STEP+1)

IF (NPTS.LE. 4096) GO TO 60

WRITE $(7,340)$ NPTS

GO TO 20

60 COHT INUE

CALL MCLI (AADC, ISTAT)

$\mathbf{c}$

EXPAND DI8PLAY TO $10 K$ X NPTS

$\operatorname{TOP}(1)=0$

$\operatorname{TOP}(2)=1000$

IST $=1$

CALL ASPP ( 1 , IST, ITPT, BOT, TOP, IEAR

IF (ISTAT. EQ. 1 ) GO TO 70

WRITE $(7,350)$

WRITE $(7,270)$

READ $(5,360)$ YN

IF (YN NE. YES) GO TO 70

CALL F.XIT

70 CONTINUE

NPT $=$. STOP( 1) - START (1) )/8TEP+ 1

NTPT $=$ ND IA*NPT

86 CALL MCLI (ERASE, IERR)

DO $160 \mathrm{~L}=1$, NDIA 


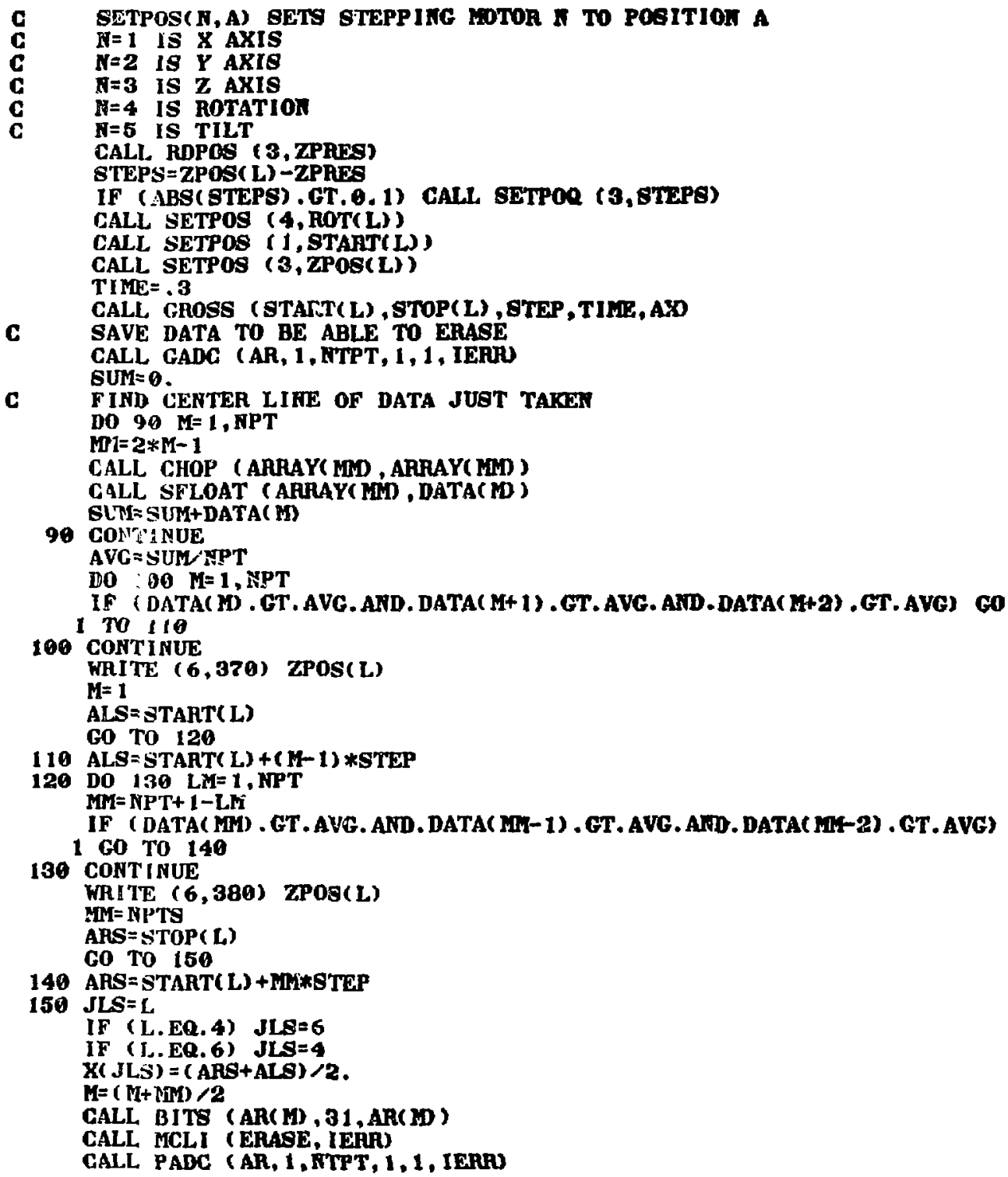


IF (i.EQ. RDIA) CO TO 160

C GADA ( AR, 1, NPT $, 1,1$, IERH)

$1 S C=(N D I A-L) * N P T+1$

IEC $=($ NDI IA-L +1$) *$ NPT

CALL PADC (AR, ISC, IEC, 1, 1, JERTU

C ZERO OUT LOWER AREA

CALL PADC (ZERO, 1, NPT, 1, 1, IERD)

DIFF $=\operatorname{AMAX1}(X(1), X(2), X(3))-\operatorname{AMINL}(X(1), X(2), X(3))$

IF (L.EQ.3.AND.DIFF.LT.0.03) GO TO 920

C

PHOGRAM CETERLINE (SOURCE, CL)

$W=57.29578$

CM $=1.6$

$C \theta=(X(2)-X(3))-(X(1)-X(3)) *((X(5)-X(6))-(X(4)-X(6)))$

$C_{1}=(\operatorname{ZPOS}(2)-\operatorname{ZPOS}(3))-(\operatorname{ZPOS}(1)-\operatorname{ZPOS}(3)) *((x(8)-X(6)) /(X(4)-X(6)))$

$\mathrm{C}=-\mathrm{CO} / \mathrm{C1}$

$B=(-C *(Z P O S(2)-Z P O S(3))-(X(2)-X(3))) /(X(6)-X(6))$

$A=-X(3)-B * X(6)-C * Z P O S(3)$

$\mathrm{ABI}=1+\mathrm{B} * \mathrm{~B}+\mathrm{C} * \mathrm{C}$

IF (ABI.LT.O) $A B I=-A B I$

$\mathrm{XD}=\operatorname{SenT}(\mathrm{AB}$ ( )

$\mathrm{AB}=1 .<\mathrm{XP}$

$\mathrm{BB}=\mathrm{B} / \mathrm{XD}$

$\mathbf{C B}=\mathbf{C}, \mathrm{XD}$

$A C A=1,-C B * C B$

IF (ACA.LT. O) ACA $=-A C A$

ACB $=$ SORT (ACA)

$\mathrm{ABC}=\mathrm{ACB} / \mathrm{CB}$

$C C=A \operatorname{TAN}(A B C)$

IF (CC. LT. 0.) CC=CC+3. 14159

$\mathrm{CC}=\mathrm{CC} * \mathrm{~W}$

$\mathrm{ZD}=\mathrm{BB} / \mathrm{SIN}(\mathrm{CC} / \mathrm{H})$

$A B B=1,-Z D * Z D$

IF (ABB.LT, 0.) ABB =-ABE

$B B B=$ SORT (ABB)

$B B C=B 13 B / Z D$

$\mathrm{D}=\mathrm{ATAN}(\mathrm{BBC})$

IF (D.LT.0.) $D=D+3.14159$

$\mathrm{D}=\mathrm{D} * \mathrm{~W}$

$\mathrm{ZE}=-90 .+\mathrm{D}$

$\mathrm{C} 4=90 .-\mathrm{CC}$

$\mathrm{RF}=\mathrm{RO}+\mathrm{ZE} / 1800$

C $\quad \mathrm{TA}=\mathrm{SIN}(\mathrm{C} 4 / \mathrm{W}) / \mathrm{Cos}(\mathrm{C} 4 / \mathrm{W})$

TO PILLSET TILT POSITION

$\mathrm{TF}=(Z L * C M * T A+T O)$

WRITT: $(6,490)$

IF (TF.LT.TUL) GO TO 170

WRITE $(6,390)$ TF, TUL

TF $=$ TUL

co To 180 
170 IF (TF.GT.TLL) GO TO 160

WRITE $(6,40 \theta)$ TF, TLL

$\mathrm{DF}=\mathrm{DF}-.100$

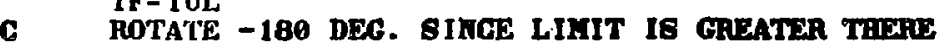

180 CONT INUE

WRITE $(6,270)$

WRITE $(6,410)(X(L), L=1,6)$

CL $1=(X(1)+X(2)+X(3)) / 3$.

$C L 2=(X(4)+X(5)+X(6)) / 3$.

WRITE $(6,420)$ CLI, CL2

D IF $1=\operatorname{AMAKI}(\mathrm{X}(1), \mathrm{X}(2), \mathrm{X}(3))-\operatorname{AMIN1}(\mathrm{X}(1), \mathrm{X}(2), \mathrm{X}(3))$

D IF2= AMAXI $(X(4), X(5), X(6))-A M I N I(X(4), X(5), X(6))$

IF (DIFMIN.LE.DIF1) GO TO 190

DIFHIN=DIF I

ROTMIN= ROT( 1)

TLTMIN= TO

CLMIN $=$ CLI

190 IF (DIFHIN.LE. DIF2) CO TO 200

DIFMIN=D IF2

FORMIN=ROT( 4)

TLTMI N= TO

CLMI $N=$ CL2

200 CONT INUE

WR ITE $(6,430)$ DIF 1, DIF2, DIFHIN, ROTHIN, TLTMIN, CLMIN

WR1TE $(6,440)$ (ROT $(L), L=1,6)$

WRITE $(6,460)(\operatorname{ZPOS}(L), L=1,3), \operatorname{ZPOS}(6), \operatorname{ZPOS}(5), \operatorname{ZPOS}(4)$

WITE $(6,460)$ TO, TO, TO, TO, TO, TO

WAITE $(6,270)$

WRITE $(6,470)$ RO, RF

WRITE $(6,480) \mathrm{TO}, \mathrm{TF}$

WRITE $(6,270)$

WRITE $(6,490)$

WRITE $(6,600)$

CALL SETPOS ( 5, TF)

CALL SETPOS $(4$, AF)

C CALCULATE IEW TAIGENT OF THE TITLE ANGLE,

C FROM 2000 STEPS $=1.258$ AT END OF CAPSULE

$T A=($ TT-TO $) / 2.) * 1.26 / Z$

C USE THIS TANGENT TO CORRECT BCAN POS FOR TILT

TO $=$ TF

RO $=\mathrm{RF}$

ROT (3) = RF

$\operatorname{HOT}(1)=\operatorname{ROT}(3)$

ROT (2) $=$ ROT (3)

$\operatorname{ROT}(6)=\mathrm{RF}-.050$

$\operatorname{ROT}(4)=\operatorname{ROT}(6)$

$\operatorname{ROT}(5)=\operatorname{ROT}(6)$

DOi $210 L=1$, NDIA

START $L)=X(L)+(\operatorname{ZPOS}(L)-P P) * T A-.4$

COR $=(Z P O S(L)-P P) * T A$

$\operatorname{STOP}(L)=\operatorname{BTART}(L)+. B$

210 CONT I NUE 
GO TO 80

220 ConTI IUE

WRITE $(6,510) X(1), X(2), X(3), D I F F$

WRITE $(6,520)$ ZPOS( 1$), Z 2003(2), Z$ ZPOS( 8)

WRITE $(6,530)$ RO

CALL ADPOS $(5, T 0)$

WRITE $(6,540)$ To

$\mathrm{CL}=(\mathrm{X}(1)+\mathrm{X}(2)+\mathrm{X}(3)) / 3$.

WRITE $(6,350)$ CL

CALL SETPOS $(1$, CL)

STOP

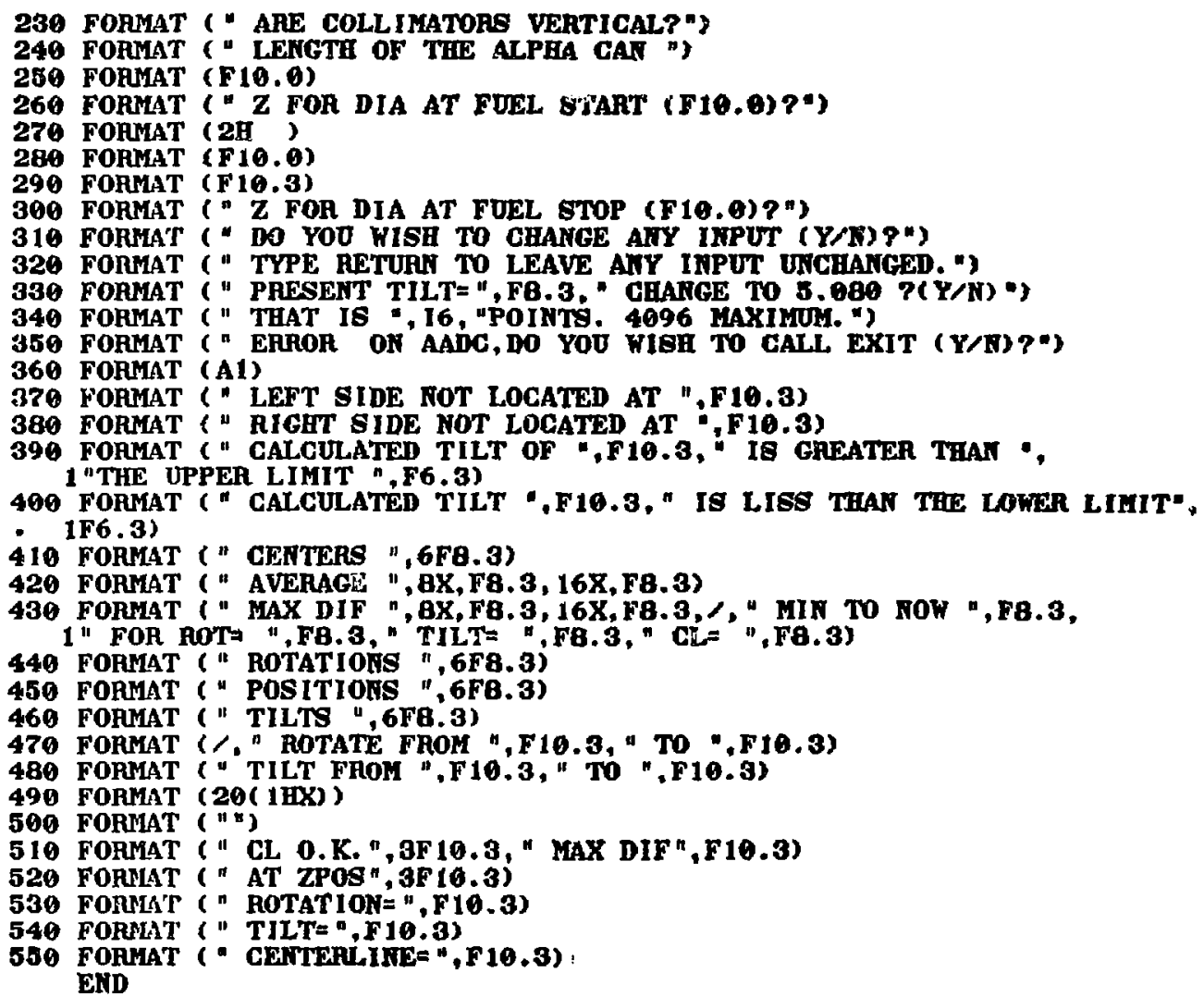

